\title{
Effect of calf starter feeding on gut microbial diversity and expression of genes involved in host immune responses and tight junctions in dairy calves during weaning transition
}

\author{
Nilusha Malmuthuge, Meiju Li, Laksiri A. Goonewardene, Masahito Oba, and Le Luo Guan ${ }^{1}$ \\ Department of Agricultural, Food and Nutritional Science, University of Alberta, Edmonton, Canada T6G 2P5
}

\begin{abstract}
Calf starters are usually offered to dairy calves to facilitate the weaning process, however, the effect of solid feed consumption on gut health has not been well studied. This study aimed to investigate the effect of calf starter feeding on the gut bacterial community and mucosal immune functions in dairy calves during weaning transition. Mucosal tissue and digesta samples were collected from rumen, jejunum, ileum, cecum, and colon upon slaughtering of calves $(\mathrm{n}=8)$ after feeding the experimental diets [milk replacer (MR) or milk replacer + calf starter $(\mathrm{MR}+\mathrm{S})]$ for $6 \mathrm{wk}$. Expression of toll-like receptor (TLR) 10 was downregulated along the gut, whereas TLR2 in colon and TLR6 along the gut were upregulated in MR+S-fed calves compared with MR-fed calves. Ileal TLR9 and TLR10 showed higher expression compared with the other regions regardless of the diet. Peptidoglycan recognition protein 1 demonstrated a diet- and gut-regional dependent expression pattern, whereas $\beta$-defensin did not. The diet and gut region also affected the expression of tight junction-regulating genes claudin 4 and occludin. Bacterial diversity tended to be different between the 2 diets, whereas the bacterial density was different among gut regions and sample type. The present study revealed that changes in bacterial diversity, expression of genes encoding host mucosal immune responses, and barrier functions were associated with the MR+S diet, and suggests that solid feed consumption may alter gut microbiome and host mucosal functions during weaning transition.
\end{abstract}

Key words: dairy calf, weaning transition, gut bacteria, innate immunity

Received September 25, 2012.

Accepted January 23, 2013.

${ }^{1}$ Corresponding author: lguan@ualberta.ca

\section{INTRODUCTION}

Feeding calf starter along with milk replacer (MR) has been practiced during weaning transition of dairy calves to facilitate the rumen development and to improve microbial fermentation in the rumen (Drackley, 2008a). Recently, it has been shown that solid feed consumption increases total VFA concentration as well as molar proportion of acetate and butyrate in the rumen of MR and starter (MR+S)-fed calves compared with calves fed only MR during weaning transition (Laarman et al., 2012). Feeding a higher amount of MR with ad libitum access to calf starter during weaning transition increased ADG, decreased postweaning calf mortality and the age at the first calving compared with calves fed limited amounts of MR (8-10\% of body weight; Drackley, 2008a). Hence, this feeding strategy provides biologically appropriate fuels, which is considered to enhance the early growth (Drackley, 2008b). However, no evidence exists as to whether such feeding effects gut health in calves.

Recent studies have shown that gut microbiome play important roles in the host metabolism, immune responses, and regulation of gastrointestinal tract (GIT) functional and morphological development (Guarner, 2006), and the host diets can alter the GIT microbial diversity (De Filippo et al., 2010; Maslowski and Mackay, 2011). Specific commensal microbes have been reported to modulate host immune responses via proinflammatory and anti-inflammatory pathways, as well as epithelial cell mediated signals (Klaenhammer et al., 2012). Pattern recognition receptors present on host cells, including toll-like receptors (TLR), are capable of recognizing highly conserved microbial molecules and initiating the previously mentioned processes (Chang, 2008; Abreu, 2010). Moreover, the interactions between commensal microbes and TLR can affect intestinal integrity (Rakoff-Nahoum et al., 2004) and mucosal barrier functions (Abreu, 2010; Ulluwishewa et al., 2011). Recently, the expression of bovine TLR and antimicrobial defense molecules have been reported to display age- and gut-regional dependent patterns and to have 
a strong correlation with mucosa-associated bacterial density along the gut, which was distinct from the correlations observed with digesta-associated community in dairy calves (Malmuthuge et al., 2012b).

The diet-associated changes in the gut microbiome and the influence of gut microbes on host immune mechanisms have been studied in mice, humans, and pigs. However, very limited information exists on how gut microbiome would be affected by solid feed consumption in dairy calves. Thus, this study explored the diet-associated changes in commensal bacteria and mucosal functions in terms of the expression of pattern recognition receptors (bovine TLR), antimicrobial defense molecules ( $\beta$-defensin and peptidoglycan recognition protein 1) and tight junctions ( $\mathbf{T} \mathbf{J}$; claudin 1 , claudin 4 , and occludin) using mRNA abundance level in dairy calves during weaning transition to identify the specific effect of calf starter consumption on GIT functions.

\section{MATERIALS AND METHODS}

\section{Animal Experiment and Sample Collection}

This is a companion study analyzing samples collected from selected animals used in the study of Laarman et al. (2012). Eight Holstein bull calves were purchased from a commercial dairy farm at 2-wk-old and then housed in individual pens at Laird W. McElroy Metabolism and Environment Research Unit at University of Alberta. All the experimental protocols were reviewed and approved by the Livestock Animal Care committee of the University of Alberta and all the procedures were carried out following the guidelines of Canadian Council on Animal Care. Calves were paired based on BW and, for each pair, one calf was assigned to a commercial MR diet (22\% CP, $17 \%$ fat, and $45 \%$ lactose; Grober Nutrition, Cambridge, Ontario) and the other calf was fed MR and starter (starter $=29.5 \% \mathrm{CP}$, $27.1 \%$ starch; Wetaskiwin Co-Op Country Junction, Wetaskiwin, Alberta). All calves were provided with water and hay ad libitum and $750 \mathrm{~g} /$ day of MR. The $\mathrm{MR}+\mathrm{S}$-fed calves received ad libitum calf starter and the MR-fed calves received extra MR to balance metabolizable energy intake within a pair. When calves in the $\mathrm{MR}+\mathrm{S}$ group started to consume $680 \mathrm{~g} /$ day of calf starter for 3 consecutive days, both calves in each pair were euthanized ( $49 \pm 5.2 \mathrm{~d}$ of age). Mucosal tissue and digesta samples were collected from rumen, jejunum, ileum, cecum, and colon of the GIT and were snap frozen in liquid nitrogen and stored at $-80^{\circ} \mathrm{C}$ until further analysis. Mucosal tissue samples were collected from the same site consistently for all the animals. Ileum samples were collected from proximal end of ileo-cecal fold (30 $\mathrm{cm}$ proximal to ileo-cecal junction), jejunum samples were collected from $1 \mathrm{~m}$ distal to the pylorus sphincter, and colon samples were collected from $30 \mathrm{~cm}$ distal to the ileo-cecal junction.

\section{DNA Extraction and Profiling of Bacterial Phylotypes}

Total DNA Extraction. Total DNA was extracted from all the samples using bead-beating method described in previous studies (Li et al., 2009). Briefly, samples were subjected to physical disruption using BioSpec mini beads beater 8 (BioSpec, Bartlesville, OK) at 5000 rpm for $3 \mathrm{~min}$, followed by phenol:chloroform:isoamyl alcohol (25:24:1) extraction and cold ethanol precipitation of DNA. After dissolving precipitated DNA in nuclease-free water, quality and quantity was measured using an ND 1000 spectrophotometer (NanoDrop Technologies, Wilmington, DE) and stored at $-20^{\circ} \mathrm{C}$.

PCR-Denaturing Gradient Gel Electrophoresis. Profiling of predominant bacterial phylotypes present in mucosal tissue and digesta communities of the GIT of dairy calves fed with differing diets was performed using PCR-denaturing gradient gel electrophoresis (DGGE) analysis. First, the V2-V3 region $(\sim 200 \mathrm{bp})$ of $16 \mathrm{~S}$ rRNA was amplified using HDA1GC (5'-CGCCCGGGGCGCGCCCCGGGCGGGGCGGGGGCACGGGGGGACTCTACGGGAGGCAGCAGT-3') and HDA2 (5'-GTATTACCGCGGCTGCTGCTGGCAC-3') primers (Walter et al., 2000) using conventional PCR for digesta samples. Nested PCR was performed using 27F (5'-AGAGTTTGATCMTGGCTCAG-3') and 1492R (5'-TACGGYTACCTTGTTACGACTT-3') primers (Weisburg et al., 1991) followed by HAD1-GC and HDA2 for tissue samples. Then, the PCR products ( $200 \mathrm{bp})$ were run on $6 \%$ polyacrylamide gels with 30 to $55 \%$ gradient using Bio-Rad DCode Universal Mutation Detection System (Bio-Rad Laboratories Inc., Hercules, CA) at $130 \mathrm{~V}$ and $60^{\circ} \mathrm{C}$ for $4 \mathrm{~h}$.

Analysis of PCR-DGGE Band Patterns. Bionumerics software package version 6.0 (Applied Maths, Austin, TX) was used to analyze all the obtained PCR-DGGE profiles. Dendrograms were produced to compare similarity between PCR-DGGE profiles under 2 diets, using unweighted pair group with mathematical averages (UPGMA) at 1\% position tolerance. Best fit of Gaussian curve for each band was used to determine the total number of bands present in all samples, following the method described by Hernandez-Sanabria et al., (2010). Each PCR-DGGE band was then considered as a distinctive bacterial phylotype. Bacterial phylotypes richness of a particular gut region was defined as the total number of bands present in each mucosal tissue and digesta sample. Relative abundance of shared phy- 
lotypes between mucosal tissue and digesta was calculated by dividing the number of shared bands by the total number of bands in each gut region.

\section{Analysis of Total Bacteria and Lactic Acid Bacteria Populations}

Quantitative real-time PCR (qRT-PCR) was performed to estimate the copy number of $16 \mathrm{~S}$ rRNA genes of total bacteria and lactic acid bacteria (LAB) using SYBR green chemistry (Fast SYBR Green Master Mix, Applied Biosystems, Foster City, CA) with StepOnePlus Real-Time PCR System (Applied Biosystems). Copy number of total bacteria was estimated using U2 primers (U2F, 5'-ACTCCTACGGGAGGCAG-3'; U2R, 5'- GACTACCAGGGTATCTAATCC-3'; Stevenson and Weimer, 2007). A serial dilution of plasmid DNA containing full-length $16 \mathrm{~S}$ rRNA gene of Butyrivibrio hungate $i$ was used to generate a standard curve for total bacterial $16 \mathrm{~S}$ rRNA copy number evaluation. The copy number of LAB was estimated using universal LAB primer Lac1 (5'-AGCAGTAGGGAATCTTCCA-3') and Lac2 (5'-ATTTCACCGCTACACATG-3'; Walter et al., 2001). The standard curve for LAB was constructed using a serial dilution of purified full-length 16S rRNA gene amplified from genomic DNA of Lactobacilli acidophilus ATCC4356. The copy number of 16S rRNA genes per gram of fresh digesta or tissue was calculated using following equation ( $\mathrm{Li}$ et al., 2009)

$$
(\mathrm{QM} \times \mathrm{C} \times \mathrm{DV}) /(\mathrm{S} \times \mathrm{W}),
$$

where QM was the quantitative mean of copy number obtained from qRT-PCR; $\mathrm{C}$ was the DNA concentration of each sample $(n g / \mu \mathrm{L})$; DV was the dilution volume of extracted DNA $(\mu \mathrm{L})$; S was the DNA amount subjected to the qRT-PCR analysis (ng); and $\mathrm{W}$ was the sample weight subjected to the DNA extraction (g). The LAB proportion was calculated by dividing the $16 \mathrm{~S}$ rRNA genes copy number of LAB by the total bacterial $16 \mathrm{~S}$ rRNA genes copy number.

\section{RNA Extraction and Expression of Innate Immune Genes and Tight Junctions}

Very low level of expression in TLR and antimicrobial defense molecules of the rumen mucosal tissue observed in a previous study (Malmuthuge et al., 2012b) suggests that GIT play an important role in mucosal immune system compared with the rumen. Therefore, in the present study, RNA was extracted only from jejunum, ileum, cecum, and colon tissue samples. Samples were homogenized with TRIzol (Invitrogen,
Grand Island, NY) by using CK-14 Precelleys lysine kit (Bertin Technologies, Montigny, France) in a Precelleys homogenizer. Then, RNA was precipitated using cold ethanol, following the chloroform, isopropanol, and high salt solution $(1.2 \mathrm{M} \mathrm{NaAc}, 0.8 \mathrm{M} \mathrm{NaCl})$ treatments and dissolved in nuclease-free water $(200 \mu \mathrm{L})$. The RNA quantity was measured using ND 1000 spectrophotometer (NanoDrop Technologies, Wilmington) and RNA integrity number was measured using Bioanalyzer 2100 (Agilent Technologies, Santa Clara, CA).

The qRT-PCR analysis was performed to evaluate the expression of genes encoding 10 bovine TLR, $\beta$-defensin, peptidoglycan recognition protein 1 (PGLYRP1), and TJ (claudin 1, claudn 4, and occludin) along the GIT of dairy calves under 2 diets during weaning transition using the primers listed in Table 1. $\beta$-Actin was chosen as the housekeeping gene out of 4 genes tested with all the mucosal tissue samples (GAPDH, ribosomal protein large P0, and 18S) using geNorm analysis (Vandesompele et al., 2002). Amplified RNA was generated from the total RNA using Ambion Allyl Message Amp II aRNA kit (\#1753; Ambion Inc., Grand Island, NY) and used for qRT-PCR analysis. The relative expression of genes of interest was then measured with gene specific primers (Table 1), using StepOnePlus Real-Time PCR System (Applied Biosystems). The qRT-PCR was performed using $1 \mu \mathrm{l}$ of $50 \mathrm{ng} / \mu \mathrm{l}$ of amplified RNA as the template and the following program: $95^{\circ} \mathrm{C}$ for $15 \mathrm{~s}$, followed by 40 cycles of $95^{\circ} \mathrm{C}$ for $3 \mathrm{~s}$ and $60^{\circ} \mathrm{C}$ for $30 \mathrm{~s}$. Finally, a melt curve was generated at $95^{\circ} \mathrm{C}$ for $15 \mathrm{~s}, 60^{\circ} \mathrm{C}$ for $1 \mathrm{~min}$, and $95^{\circ} \mathrm{C}$ for $15 \mathrm{~s}$. Gene expression ( $\Delta \mathrm{Cq}$ value) was calculated based on quantification cycle $(\mathrm{Cq})$ of housekeeping gene ( $\beta$-actin) and target gene (TLR, $\beta$-defensin, PGLYRP1, TJ; $\Delta \mathrm{Cq}=\mathrm{Cq}$ target gene $-\mathrm{Cq}$ housekeeping gene) .

\section{Statistical Analysis}

All the data were analyzed using MIXED procedure in SAS (version 9.2; SAS Institute Inc., Cary, NC) with gut region as the repeated measurement and animal as the experimental unit using compound symmetry covariance structure, which was selected as the best fit by the Bayesian information criterion. Determined by

$$
\begin{aligned}
\mathrm{Y}_{\mathrm{ijkl}} & =\mu+\mathrm{D}_{\mathrm{i}}+\mathrm{G}_{\mathrm{j}}+\mathrm{S}_{\mathrm{k}}+\mathrm{DG}_{(\mathrm{ij})} \\
& +\mathrm{DS}_{(\mathrm{ik})}+\mathrm{GS}_{(\mathrm{jk})}+\mathrm{e}_{\mathrm{ijk} \mathrm{k}}
\end{aligned}
$$

where $\mathrm{Y}=$ observation [phylotype richness, relative abundance of shared bands, total bacterial density, LAB proportion, gene expression ( $\Delta$ Cq value) $; \mu=$ mean; $\mathrm{D}$ $=$ diet effect; $\mathrm{G}=$ gut region effect; $\mathrm{S}=$ sample type 


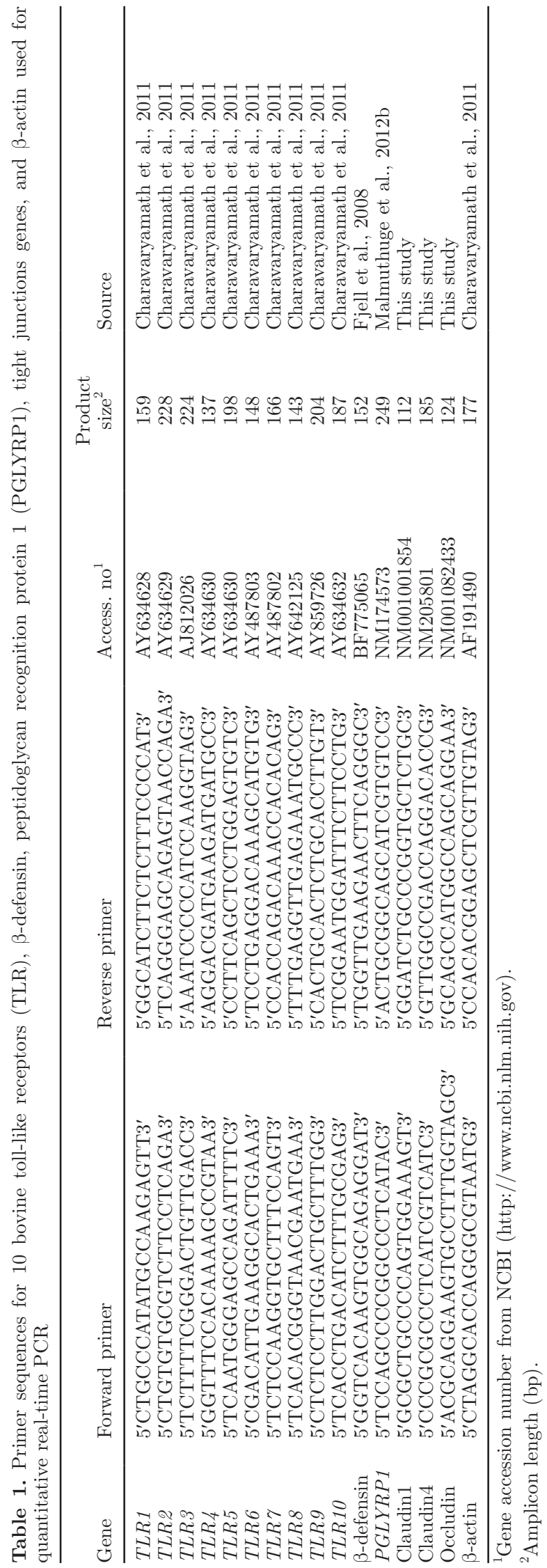

effect; $\mathrm{DG}=$ diet by gut region interaction; $\mathrm{DS}=$ diet by sample type interaction; GS = gut region by sample type interaction; and $\mathrm{e}=$ residual error.

In the analysis of relative abundance of shared bands and gene expression data, sample type (S) was not a source of variation and was not included in the statistical models. Differences in LSM were declared at $P<$ 0.05 using the PDIFF option in SAS when applicable.

\section{RESULTS}

\section{Predominant Bacterial Phylotypes Richness Along GIT}

Feeding calf starter during weaning transition tended to increase richness (PCR-DGGE band counts) of predominant phylotypes along the GIT of calves compared with only MR-fed calves (Table 2; $P=0.10$ ). However, gut-regional $(P<0.01)$ and sample-type $(P=0.05)$ dependent bacterial richness was observed along the GIT of calves regardless of the diet. Rumen had the highest richness compared with all other gut regions in both mucosal tissue and digesta communities, whereas mucosal tissue community richness was higher than that of digesta community (Table 2). In addition, none of the interactions had a significant effect on the bacterial richness $\left(P_{\mathrm{DG}}=0.14, P_{\mathrm{DS}}=0.21, P_{\mathrm{GS}}=0.42\right.$, where $\mathrm{DG}=\operatorname{diet} \times$ gut region, $\mathrm{DS}=\operatorname{diet} \times$ sample type, and $\mathrm{GS}=$ gut region $\times$ sample type). Relative abundance of shared bacterial phylotypes between mucosal tissue and digesta was not different between the 2 diets $(P=$ $0.54)$, though it was different among the gut regions (Table 3; $P<0.01$ ). Rumen and large intestine (cecum, colon) shared more phylotypes between 2 communities, compared with the small intestine (jejunum, ileum), regardless of the diet.

\section{Total Bacteria and LAB Populations}

No significant difference was observed in total bacteria population and LAB proportion between MR- and $\mathrm{MR}+\mathrm{S}$-fed calves (Table 4). Total bacteria population was different between mucosal tissue and digesta (Table 4; $P=0.05)$, and the mucosa-associated bacterial density was lower than that of digesta-associated bacterial density. The LAB proportion was highest in jejunum, followed by ileum, compared with the other gut regions (Table $4 ; P<0.01$ ).

\section{Mucosal Innate Immune Genes Expression}

In this study, the expressions of genes of interest were measured at the mRNA level using qRT-PCR relative to $\beta$-actin expression level using the $\Delta \mathrm{Cq}$ value. Higher 
Table 2. Numbers of predominant bacterial phylotypes in the gut under MR or MR+S diets during weaning transition

\begin{tabular}{|c|c|c|c|c|c|c|c|c|c|c|c|c|}
\hline \multirow[b]{2}{*}{ Item } & \multicolumn{3}{|c|}{ Diet $^{1}$} & \multicolumn{3}{|c|}{ Sample type } & \multicolumn{6}{|c|}{ Gut region } \\
\hline & MR & $\mathrm{MR}+\mathrm{S}$ & SEM & Tissue & Digesta & SEM & Rumen & Jejunum & Ileum & Cecum & Colon & SEM \\
\hline $\begin{array}{l}\text { Band count }{ }^{2} \\
P \text {-value }\end{array}$ & 29 & $\begin{array}{l}34 \\
0.10\end{array}$ & 2 & $35^{\mathrm{a}}$ & $\begin{array}{l}28^{\mathrm{b}} \\
0.05\end{array}$ & 2 & $39^{\mathrm{x}}$ & $26^{\mathrm{y}}$ & $\begin{array}{l}30^{\mathrm{y}} \\
<0.01\end{array}$ & $30^{y}$ & $31^{\mathrm{y}}$ & 2 \\
\hline
\end{tabular}

$\overline{\mathrm{a}, \mathrm{b} / \mathrm{x}, \mathrm{y}}$ Means with the same superscript within row are not significantly different between sample types or among gut regions at $P<0.05$.

${ }^{1} \mathrm{MR}=$ milk replacer; $\mathrm{MR}+\mathrm{S}=$ milk replacer + calf starter.

${ }^{2}$ Each PCR-denaturing gradient gel electrophoresis (DGGE) band is considered as a distinctive bacterial phylotype and total numbers of PCRDGGE bands were used to define the richness.

$\Delta \mathrm{Cq}$ value represents lower mRNA abundance or gene expression and vice versa. Diet- and gut-regional dependent expression was observed in TLR along the GIT of dairy calves when calf starter was added to the preweaned diet (Table 5). The expression of TLR6 and TLR10 was diet dependent $(P<0.01)$, whereas the expression of TLR9 and TLR10 was gut-region dependent $(P<0.01)$. In addition, diet-dependent expression trends were observed in TLR 3, 4, and 5, whereas gut-region dependent expression trend was observed in TLR6 (Table $5 ; P=0.08$ ). A diet by gut region interaction effect $(P=0.03)$ was observed for the expression level of TLR2. Expression of TLR2 in the colon was significantly different between 2 diets (Figure 1), and was higher in the ileum and colon compared with jejunum and cecum in the MR+S-fed calves (Figure 1). In all the gut regions of calves fed with MR+S, TLR6 was upregulated and TLR10 was downregulated (Table 5). Expression of TLR 9 and TLR10 was highest in the ileum compared with other gut regions irrespective of the diet (Table 5).

Expression of $\beta$-defensin was not significantly different either between the 2 diets or among gut regions (Table 5). However, its expression tended to be lower in starter-fed calves compared with only MR-fed calves (Table 5; $P=0.08$ ). Expression of PGLYRP1 was both diet- and gut-regional dependent along the GIT of calves during weaning transition (Table 5). The PGLYRP1 expression was upregulated in calves fed with $\mathrm{MR}+\mathrm{S}$ compared with the calves fed with only MR (Table 5; $P$ $<0.01)$. The PGLYRP1 had a higher expression level in jejunum and ileum than in cecum and colon of dairy calves (Table 5). Diet by gut-region interaction revealed a tendency $(P=0.06)$ to alter PGLYRP1 expression in the GIT of calves during weaning transition.

\section{Intestinal TJ}

In the present study diet- and gut-regional dependent expression pattern was observed in the TJ genes along the GIT of calves during weaning transition. Claudin 1 expression was not significantly different either between calves fed the 2 different diets (Figure 2; $P=$ $0.20)$ or among gut regions $(P=0.14)$, also the diet by gut-region interaction effect was not significant $(P=0.79)$. However, diet by gut-regional dependent expressions was observed in claudin 4 and occludin (Figure 2). Both claudin 4 and occludin expressions were downregulated in $\mathrm{MR}+\mathrm{S}$-fed calves compared with MR-fed calves. Claudin 4 expression was lowest in the ileum of calves fed with $\mathrm{MR}+\mathrm{S}$ compared with all other regions (Figure 2). Claudin 4 expression was significantly downregulated in the ileum and jejunum of the MR+S-fed calves, whereas expression of occludin was significantly downregulated in the jejunum, ileum, and cecum of MR+S-fed calves compared with that of MR-fed calves (Figure 2).

\section{DISCUSSION}

Previous studies reported that diet is one of the main factors that can change the diversity of gut microbial

Table 3. Relative abundance of shared bacterial phylotypes between mucosa- and digesta-associated communities in the gastrointestinal tract

\begin{tabular}{|c|c|c|c|c|c|c|c|c|c|}
\hline \multirow[b]{2}{*}{ Item } & \multicolumn{3}{|c|}{$\operatorname{Diet}^{1}$} & \multicolumn{6}{|c|}{ Gut region } \\
\hline & MR & $\mathrm{MR}+\mathrm{S}$ & SEM & Rumen & Jejunum & Ileum & Cecum & Colon & SEM \\
\hline $\begin{array}{l}\text { Shared bands }{ }^{2} \\
P \text {-value }\end{array}$ & 0.22 & $\begin{array}{l}0.20 \\
0.54\end{array}$ & 0.02 & $0.29^{\mathrm{a}}$ & $0.15^{\mathrm{b}}$ & $\begin{array}{l}0.15^{\mathrm{b}} \\
<0.01\end{array}$ & $0.23^{\mathrm{a}}$ & $0.24^{\mathrm{a}}$ & 0.03 \\
\hline
\end{tabular}

${ }^{\mathrm{a}, \mathrm{b}}$ Means with the same superscript within row are not significantly different among gut regions at $P<0.05$.

${ }^{1} \mathrm{MR}=$ milk replacer; $\mathrm{MR}+\mathrm{S}=$ milk replacer + calf starter.

${ }^{2}$ Proportion of shared PCR-denaturing gradient gel electrophoresis bands between mucosa and digesta or total number of bands in each gut region. 


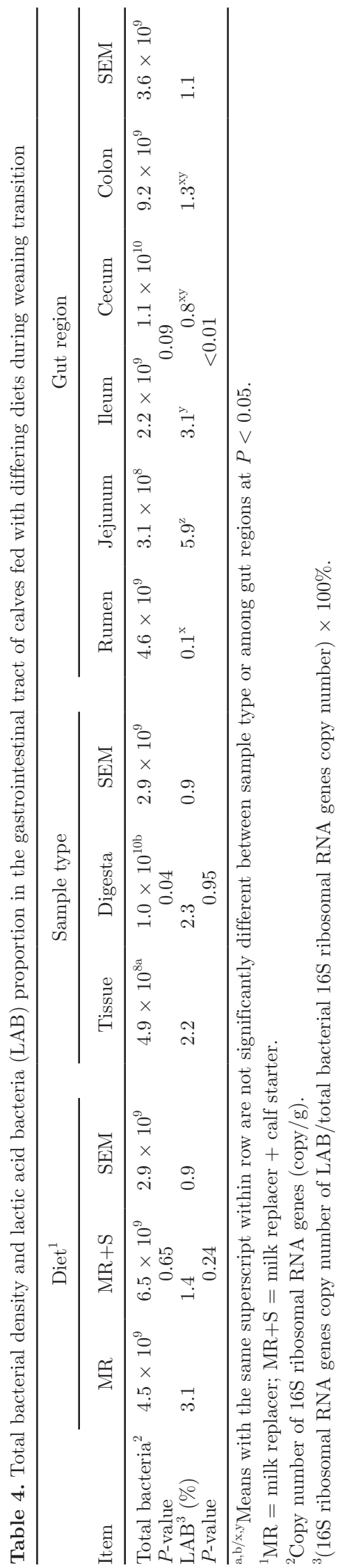

community (Ley et al., 2008; De Filippo et al., 2010; Maslowski and Mackay, 2011). However, the analysis of detectable bacterial PCR-DGGE profiles in the present study did not reveal a clear segregation of the bacterial profiles between the $\mathrm{MR}$ and $\mathrm{MR}+\mathrm{S}$ diets (data not shown). As milk replacer was a major component in their diet for both groups of calves (MR vs. $\mathrm{MR}+\mathrm{S}$ ), it might have masked the effect of starter intake on bacterial diversity. Nonetheless, solid feed consumption tended to increase the PCR-DGGE band counts in the calves gut, indicating changes in the bacterial diversity in terms of richness. Higher phylotypes richness with solid feed consumption was noticeable in the rumen compared with other gut regions (mucosal tissue $=$ 35 vs. 45 , and digesta $=30$ vs. 44 ), suggesting that starter feeding tended to increase the richness of the rumen microbial community. Higher bacterial richness observed in the present study, and the elevated levels of total VFA and proportions of acetate and butyrate reported by Laarman et al., (2012) using the same $\mathrm{MR}+\mathrm{S}$-fed calves, suggests that solid feed consumption may enhance the bacterial activity to facilitate the rumen development during weaning transition. However, the observed change in bacterial phylotypes richness in the rumen with the solid feed consumption was not significant, which might be a result of the high individual variation and fewer number of animals tested. The observed regional and sample-type dependent bacterial phylotypes richness confirmed our similar findings from calves fed with milk (Malmuthuge et al., 2012a) and further suggests the effects of gut region and sample type on the GIT bacterial composition exist regardless of the diet fed to the animal.

Previous studies on gut microbiota have been mainly focused on digesta-associated community. Recent studies have shown mucosa-associated community was abundant and different than that of digesta-associated (Malmuthuge et al., 2012a), and the mucosa-associated bacterial composition can alter the TLR2 and TLR4 expressions in the colon of mice (Wang et al., 2010). It has also been reported that weaning-associated alterations in bacterial diversity attached to the mucosal tissue could increase adherence of Clostridium perfringens in the small intestine (Deplancke et al., 2002) and incidence of enteric diseases in piglets (Miclard et al., 2009). Moreover, morphological and functional development in the GIT during weaning was hindered in germ-free piglets to a greater extent compared with conventionally reared piglets and altered by the gut bacterial composition (Gancarcikova et al., 2009). These findings suggest that commensal microbes, especially the mucosa-associated microbes, may play an essential role in modulation of the development of host intestine and immune system. Our data suggest that addition 
of starter to the preweaned diet tends to change gut bacterial richness, which may eventually alter mucosal immune functions, and these changes may contribute to early weaning and better postweaning performances (Drackley, 2008a).

Gut microbial diversity is associated with dietary changes (Maslowski and Mackay, 2011); however, total bacterial density seems not to be influenced. Antibiotic treatments have been shown to reduce total bacterial population and later elevate antibiotic resistance bacterial species (Ubeda et al., 2010); they also decrease some beneficial bacteria belonging to the Ruminococcaceae and Lachnospiraceae families, which produce butyrate for host energy metabolism (Dethlefsen and Relman, 2011). Thus, maintenance of stable bacterial density along the GIT could be crucial for the host to maintain microbial fermentation and protection against any pathogenic invasion. In addition, that no changes in LAB proportion were noted when calves were fed with $\mathrm{MR}+\mathrm{S}$ suggests that calf starter has no effects on the population of these beneficial microorganisms. The population of LAB was investigated in this study due to their ability to modulate host immune system via secreting antimicrobial compounds such as bacteriocins (Cintas et al., 2001) and their uses as probiotics to treat enteric infections (Sanders and Levy, 2011). Lactic acid bacteria have been reported to stimulate host adaptive immune system via activation of mucosal $\mathrm{B}$ cells and $\mathrm{CD}^{+} \mathrm{T}$ cells (Perdigón et al., 1999) and, thus, increasing IgA production (Corthésy et al., 2007). Hence, it could be very important for calves to maintain higher or stable LAB proportions in the small intestine to stimulate gut-associated lymphoid tissues and to increase secretory IgA, both of which would boost calves' active immunity when passive immunity obtained from colostrum is diminished.

During weaning, significant morphological changes occur in the GIT, such as a reduction in villus height and crypt depth (Kuzmuk et al., 2005), as well as hyperplasia in crypts (Gancarcikova et al., 2009). However, it has been proven that morphological changes observed during weaning can be altered via the dietary ingredients (Spreenwenberg, 2002), and that these changes are associated with gut microbial composition

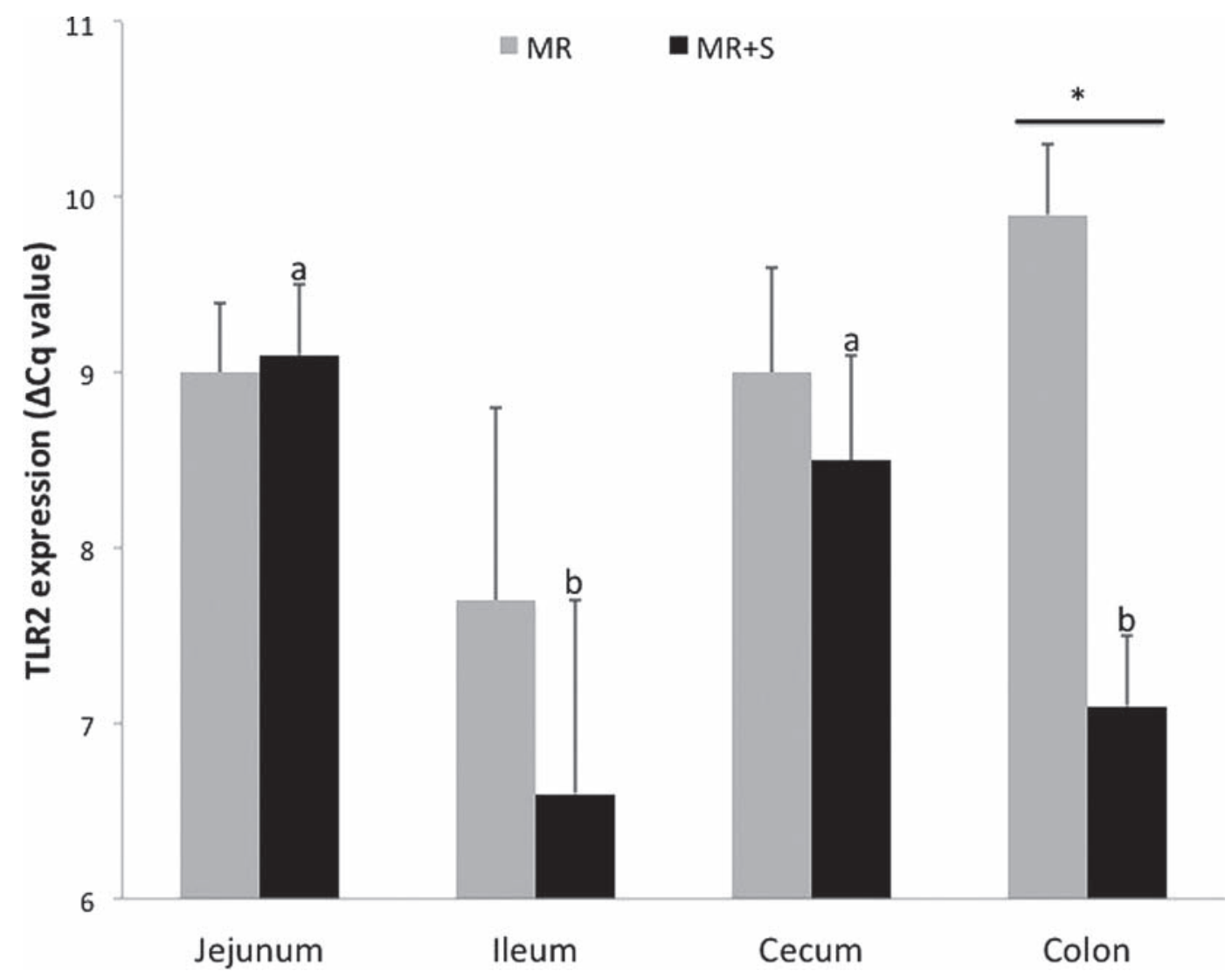

Figure 1. Diet- and gut-regional dependent expression of toll-like receptor (TLR) 2 during weaning transition of dairy calves. Gene expression $(\Delta \mathrm{Cq})=\mathrm{Cq}_{(\mathrm{TLR2})}-\mathrm{Cq}_{(\beta \text {-actin) }}$. Higher $\Delta \mathrm{Cq}$ value represents lower mRNA abundance or gene expression and vice versa. Values a,b represent effect of gut region on TLR2 expression within a diet; an asterisk represents effect of diet on TLR2 expression within a gut region. MR $=$ milk replacer; $\mathrm{MR}+\mathrm{S}=$ milk replacer + calf starter. 


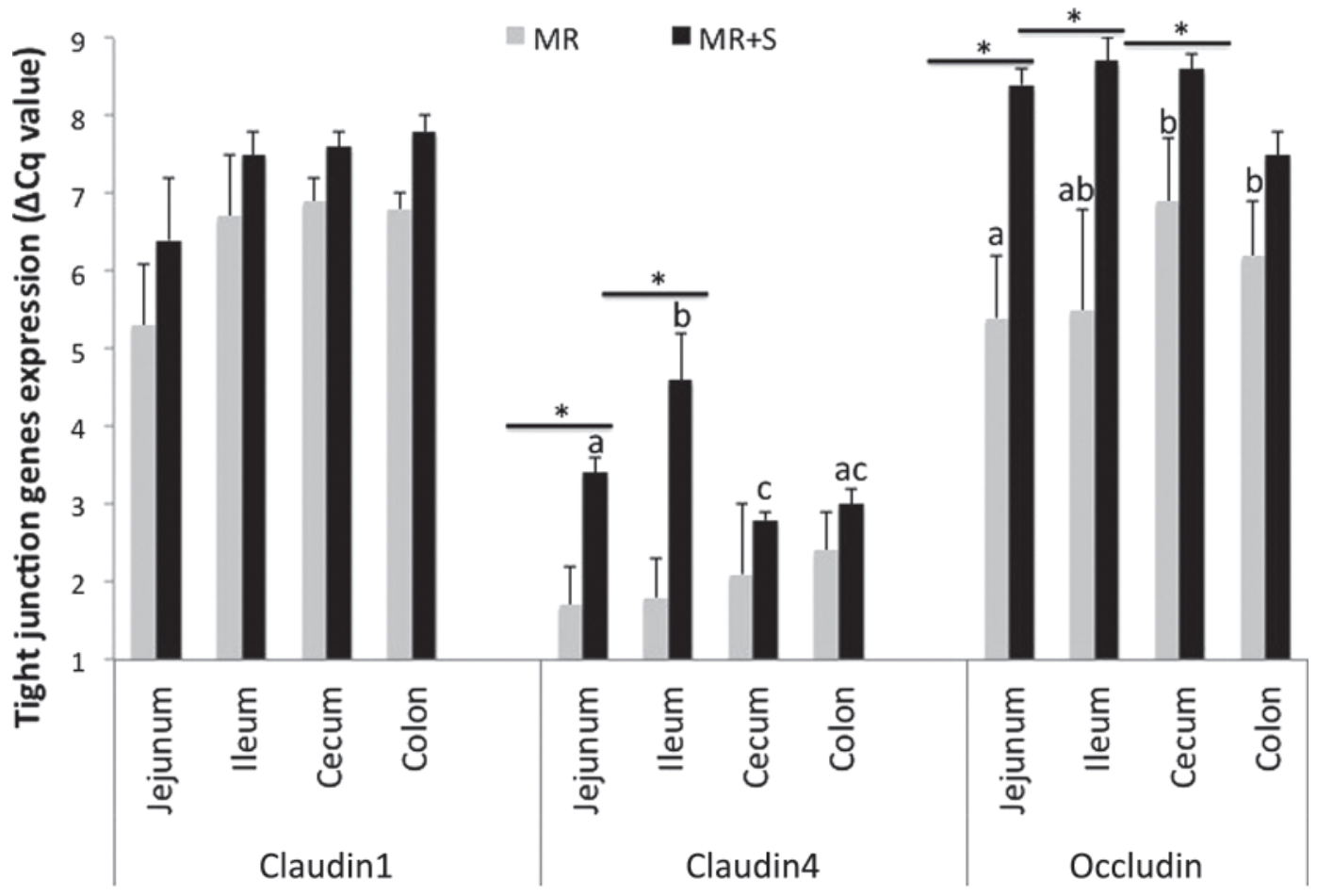

Figure 2. Expression of tight junction (TJ) genes (claudin 1, claudin 4, and occludin) in the gastrointestinal tract during weaning transition of dairy calves. Gene expression $(\Delta \mathrm{Cq})=\mathrm{Cq}_{(\mathrm{TJ})}-\mathrm{Cq}_{(\beta \text {-actin })}$. Higher $\Delta \mathrm{Cq}$ value represents lower mRNA abundance or gene expression and vice versa. Values a to c represent effect of gut region on TJ expression within a diet; an asterisk represents effect of diet on TJ expression within a gut region. $\mathrm{MR}=$ milk replacer; $\mathrm{MR}+\mathrm{S}=$ milk replacer + calf starter.

(Gancarcikova et al., 2009). Moreover, expression of inflammatory cytokines along the small intestine and colon has been reported to be associated with weaning stress in pigs (Pié et al., 2004). Therefore, the observed trend of microbial diversity changes in calves with solid feed consumption may affect host mucosal innate immune responses and gut barrier functions.
Expression of genes involved in bovine innate immune functions demonstrated their regional dependent variations, confirming the findings from our previous study (Malmuthuge et al., 2012b). The expression of TLR10 was downregulated in calves fed with $\mathrm{MR}+\mathrm{S}$ compared with MR fed calves, which is similar to the downregulation of TLR10 with increasing age of calves

Table 5. Bovine toll-like receptors (TLR) and antimicrobial defense molecules expression in the gastrointestinal tract of calves fed with differing diets during weaning transition

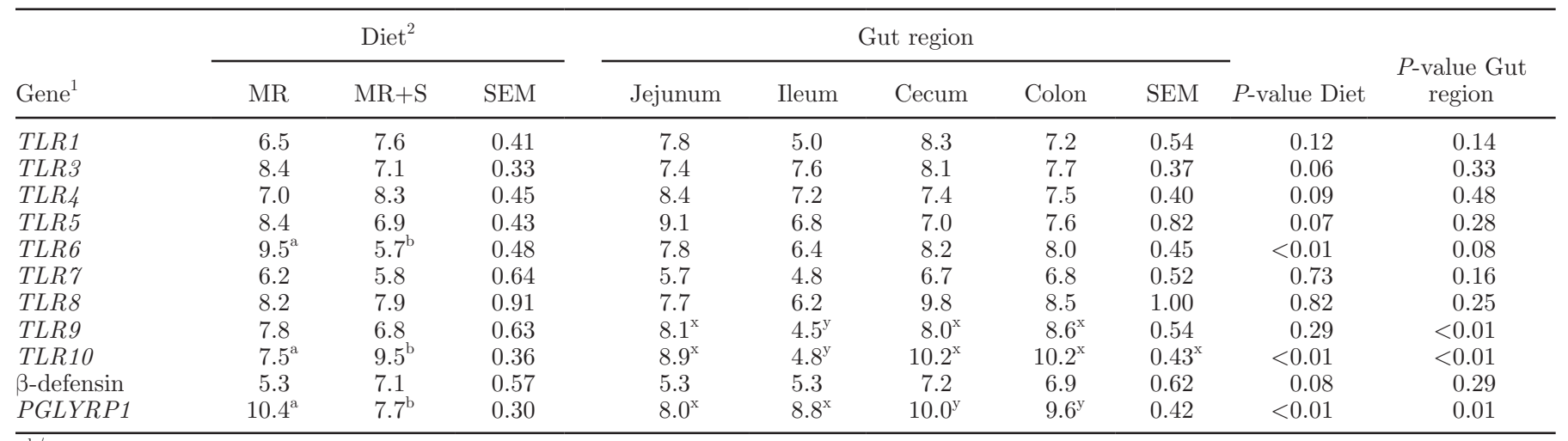

$\overline{\mathrm{a}, \mathrm{b} / \mathrm{x}, \mathrm{y}}$ Means with the same superscript within a row are not significantly different between diets or among gut regions at $P<0.05$.

${ }^{1}$ Gene expression was evaluated using relative gene expression $(\Delta \mathrm{Cq})=$ quantification cycle $(\mathrm{Cq})_{(\text {target gene) }}-\mathrm{Cq}_{(\beta \text {-actin)}}$; higher $\Delta \mathrm{Cq}$ value represents lower mRNA abundance or gene expression and vice versa.

${ }^{2} \mathrm{MR}=$ milk replacer; $\mathrm{MR}+\mathrm{S}=$ milk replacer + calf starter. 
in the gut after weaning (Malmuthuge et al., 2012b). The observed differences in TLR10 expression between the 2 diets might be an indication of variation in the gut maturity of calves due to solid feed consumption. Both studies revealed a higher expression of TLR10 in calf ileum, signifying that higher expression of TLR10 in the ileum might be very important in early mucosal immune system development. As TLR10 is a link between adaptive and innate immune responses (Guan et al., 2010), further studies on TLR10 and its functions in the GIT may lead to better understanding of the role of TLR10 in calf gut health. In the present study, both TLR2 and TLR6 displayed a diet-dependent expression along the gut. Both TLR2 and TLR6 are involved in recognizing the cell wall components of gram-positive bacteria (Melmed et al., 2003; Chang, 2008). Mutations in TLR2 have been reported to increase the susceptibility to Mycobacterium avium paratuberculosis (MAP) infection in cows (Mucha et al., 2009) and expression of TLR6 has been shown to be upregulated in small intestine of MAP-infected sheep (Plain et al., 2010). These findings suggest that TLR2 and TLR6 play very important roles in the host response to the pathogenic grampositive bacteria, including MAP in ruminants, which can directly affect gut health. Expressions of TLR2 and TLR6 were downregulated along the GIT with increasing age of calves (Malmuthuge et al., 2012b). However, the present study revealed an upregulation of both TLR2 and TLR6 with solid feed consumption during weaning transition (Figure 1). Human intestinal epithelial cells express TLR2 and TLR6 at a very low level and are unresponsive to gram-positive bacterial products (Melmed et al., 2003); however, TLR2 expression in the Lamina propria cells of inflammatory bowel disease patients has been shown to be upregulated compared to individuals without inflammatory bowel disease (Cario and Podolsky, 2000). These findings suggest that bacteria or bacterial products in the gut lumen need contact with the TLR2 and TLR6 in the mucosal tissue to upregulate their expression levels. Therefore, the observed upregulation in TLR2 and TLR6 expression in the gut of $\mathrm{MR}+\mathrm{S}$-fed calves suggests that starter feeding may have an influence on gut permeability and allows more bacterial products to breach the mucosal barrier and stimulate the expression of host pattern recognition receptors.

$\beta$-Defensin and PGLYRP1 are secretory antimicrobial defense molecules that are capable of recognizing and killing of pathogens (Dziarski and Gupta, 2006; Fjell et al., 2008; Osanai et al., 2011). $\beta$-Defensin exerts its antimicrobial activity on a broad spectrum of microbes, such as gram-negative and -positive bacteria, fungi, and viruses (Luenser and and Ludwig, 2005). Moreover, it has been reported that $\beta$-defensin regulates adaptive immune mechanisms via dendritic and $\mathrm{T}$ cell activity (Yang et al., 1999). $\beta$-Defensin expression along the GIT is not associated with either gut region (Malmuthuge et al., 2012b) or gut colonization (Renz et al., 2011), but with calf age (Malmuthuge et al., 2012b). In the present study, $\beta$-defensin expression tended to be different between MR+S- and MR-fed calves, revealing possible variations in gut maturity that occurred due to starter addition in the preweaned calf diet. Peptidoglycan recognition protein 1 mainly kills gram-positive bacteria, however bovine PGLYRP1 has an affinity to kill fungi, lipoteichoic acid, and lipopolysaccharides as well (Dziarski and Gupta, 2006). Peptidoglycan recognition protein 1 is exclusively expressed in polymorphonuclear leukocytes (Dziarski and Gupta, 2006), suggesting the need for microbial products to reach into the mucosal tissue to activate PGLYRP1. Hence, the observed upregulation in PGLYRP1 in starter-fed calves further implies the possible alterations in the gut permeability with solid feed consumption. In addition, the expression of PGLYRP1 was only observed in the GIT of weaned calves (Malmuthuge et al., 2012b). Therefore, upregulation in PGLYRP1 also indicates that MR+S-fed calf gut is more mature than MR-fed calves. Nevertheless, the observed differences in antimicrobial defense molecule expression along the GIT of calves fed with starter compared with calves fed with MR suggests that solid feed consumption may enhance mucosal immune system development.

As previously described, the upregulation of TLR2, TLR6, and PGLYRP1 expression in the GIT of calves fed with $\mathrm{MR}+\mathrm{S}$ indicates the increased gut permeability. Throughout the GIT, the mucosal epithelium provides a barrier between the host and the gut environment; it also plays a key role in recognizing the GIT microbiome and regulating the passage of nutrients, fermentation end products, and microbes, especially pathogens. Tight junctions, as one of the junction components interconnecting the paracellular spaces between epithelial cells, serve as a dynamic and strictly regulated portal of entry in response to various signals, such as ions, cytokines, and bacterial components (Anderson and Van Itallie, 2009). Members of the claudin family and occludin are the main transmembrane proteins present in the TJ that regulate the intestinal epithelial permeability and control ion and microbial product diffusion through the epithelial cell layer (Ulluwishewa et al., 2011). In mice, expression of claudin 1 did not differ among gut regions, whereas claudin 4 expression was downregulated from the duodenum to colon (Holmes et al., 2006). Similarly, claudin 1 expression did not differ among gut regions for both diets, whereas claudin 4 expression was gut-regional dependent in $\mathrm{MR}+\mathrm{S}$-fed calves. Previous studies have reported that upregula- 
tion of occludin is associated with the decreased gut permeability (Al-Sadi et al., 2011; Noth et al., 2011; Ulluwishewa et al., 2011), thus the downregulated occludin expression in the $\mathrm{MR}+\mathrm{S}$ group suggests an increase in the gut permeability, as we speculated. In addition, downregulation of claudin 4 has been reported to be associated with the increased gut permeability (Pinton et al., 2010; Sapone et al., 2011; Ulluwishewa et al., 2011; Xia et al., 2011). Lower expression of claudin 4 in the $\mathrm{MR}+\mathrm{S}$ group also suggests an increase in the gut permeability of calves fed with starter. Those results imply a possible increase in the gut permeability with starter feeding during the weaning transition. Increased gut permeability allows bacteria or bacterial products from the gut lumen to enter the mucosal tissue, which can stimulate host immune responses. Therefore, the observed differences in the expression of TLR and antimicrobial defense molecules between the 2 diets might be a result of increased permeability that allows the exposure of pattern recognition receptors and secretory molecules to the gut bacteria. Altered epithelial permeability has also been reported to be associated with the changes in gut microbes, which can subsequently affect host metabolism and gut health (Wei et al., 2012). Therefore, future studies on the effect of increased gut permeability with calf starter feeding during weaning transition on host susceptibility to enteric infections throughout life are vital to pinpoint how this feeding practice can affect gut health of cattle. Furthermore, more than 40 TJ proteins exist; future studies to investigate the expression of genes and proteins of TJ, as well as paracellular ion permeability across the gut, will provide conclusive understanding as to whether starter feeding changed gut permeability through TJ.

\section{CONCLUSIONS}

In conclusion, the present study revealed that solid feed consumption affects bacterial diversity, expression of TLR, $\beta$-defensin, PGLYRP1, claudin 4, and occludin, which belong to the first line defense mechanisms and the gut barrier functions. These changes observed in mucosal immune functions and gut maturity can be considered as another factor that facilitates early weaning and better growth in calves fed a higher amount of MR and ad libitum starter. Gene expression does not necessarily correlate with the protein expression; therefore, studies on protein expression are necessary in the future to gain a clear understanding of the effects of calf starter on mucosal immune and barrier functions. This is the first attempt to study the innate immune and TJ gene expression variations with calf starter addition to the preweaned diet. Future studies to explore changes in SCFA profile, bacterial composition, and ac- tivity, as well as gut morphology and gut permeability in response to calf starter feeding during weaning, may aid in explaining the underlying mechanisms for these variations.

\section{ACKNOWLEDGMENTS}

This work supported by a Natural Sciences and Engineering Research Council (Ottawa, Canada) Discovery Grant, Alberta Livestock and Meat Agency Ltd. (Edmonton, Canada), and Zen-Raku-Ren (Japanese Federation of Dairy Cooperative Associations, Tokyo, Japan). The authors thank the staff at the Metabolic Unit (University of Alberta) for their assistance with animal experiment.

\section{REFERENCES}

Abreu, M. T. 2010. Toll-like receptors signalling in the intestinal epithelium: How bacterial recognition shapes intestinal function. Nutr. Rev. 10:131-142.

Al-Sadi, R., K. Khatib, S. Guo, D. Ye, M. Youssef, and T. Ma. 2011. Occludin regulates macromolecule flux across the intestinal epithelial tight junction barrier. Am. J. Physiol. Gastrointest. Liver Physiol. 300:G1054-G1064.

Anderson, J. M., and C. M. Van Itallie. 2009. Physiology and function of the tight junction. Cold Spring Harb. Perspect. Biol. 1:a002584.

Cario, E., and D. K. Podolsky. 2000. Differential alteration in intestinal epithelial expression of toll-like receptor 3 (TLR3) and TLR4 in inflammatory bowel disease. Infect. Immun. 68:7010-7017.

Chang, Z. L. 2008. Role of toll-like receptors in regulatory functions of T and B cells. Chin. Sci. Bull. 53:1121-1127.

Charavaryamath, C., P. Fries, S. Gomis, C. Bell, K. Doig, L. L. Guan, A. Potter, S. Napper, and P. J. Griebel. 2011. Mucosal changes in a long-term bovine intestinal segment model following removal of ingesta and microflora. Gut Microbes 2:134-144.

Cintas, L. M., M. P. Casaus, C. Herranz, I. F. Nes, and P. E. Hernandez. 2001. Review: Bacteriocins of lactic acid bacteria. Food Sci. Technol. Int. 7:281-305.

Corthésy, B., H. R. Gaskins, and A. Mercenier. 2007. Cross-talk between probiotic bacteria and the host immune system. J. Nutr. 137:781S-790S.

De Filippo, C., D. Cavalieri, M. Di Paola, M. Ramazzotti, J. B. Poullet, S. Massart, S. Collini, G. Pieraccini, and P. Lionetti. 2010. Impact of diet in shaping gut microbiota revealed by a comparative study in children from Europe and rural Africa. Proc. Natl. Acad. Sci. USA 107:14691-14696.

Deplancke, B., O. Vidal, D. Ganessunker, S. M. Donovan, R. I. Mackie, and H. R. Gaskins. 2002. Selective growth of mucolytic bacteria including Clostridium perfringens in a neonatal piglet model of total parental nutrition. Am. J. Clin. Nutr. 76:1117-1125.

Dethlefsen, L., and D. A. Relman. 2011. Incomplete recovery and individualized responses of the human distal gut microbiota to repeated antibiotic perturbation. Proc. Natl. Acad. Sci. USA 108:4554-4561.

Drackley, J. K. 2008a. Calf nutrition from birth to breeding. Vet. Clin. North Am. Food Anim. Pract. 24:55-86.

Drackley, J. K. 2008b. Feeding pre-weaned calves for future production. Page 68-73 in Four-state Dairy Nutrition and Management Conference Proceedings, Dubuque, IA. Iowa State University, Ames.

Dziarski, R., and D. Gupta. 2006. The peptidoglycan recognition proteins (PGRPs). Genome Biol. 7:232.

Fjell, C. D., H. Jenssen, P. Fries, P. Aich, P. Griebel, K. Hilpert, R. E. W. Hancock, and A. Cherkasov. 2008. Identification of novel host defense peptides and the absence of $\alpha$-defensins in the bovine genome. Proteins 73:420-430. 
Gancarcikova, S., V. Buleca, R. Zitnan, R. Nemcova, L. Scirankova, J. Koscova, D. Mudronova, M. Hluchy, and M. Huska. 2009. Postnatal morphological development and production of short-chain fatty acids in the digestive tract of gnotobiotic piglets. Vet. Med. (Praha) 54:156-168.

Guan, Y., D. R. E. Ranoa, S. Jiang, S. K. Mutha, X. Li, J. Baudry, and R. I. Tapping. 2010. Human TLRs 10 and 1 share common mechanisms of innate immune sensing but not signaling. J. Immunol. 184:5094-5103.

Guarner, F. 2006. Enteric flora in health and disease. Digestion 73:512.

Hernandez-Sanabria, E., L. L. Guan, L. A. Goonewardene, M. Li, D. F. Mujibi, P. Stothard, S. S. Moore, and M. Leon-Quintero. 2010. Correlation of particular bacterial PCR-denaturing gradient gel electrophoresis patterns with bovine ruminal fermentation parameters and feed efficiency traits. Appl. Environ. Microbiol. 76:6338-6350.

Holmes, J. L., C. M. Van Itallie, J. E. Rasmussen, and J. M. Anderson. 2006. Claudin profiling in the mouse during postnatal intestinal development and along the gastrointestinal tract reveals complex expression patterns. Gene Expr. Patterns 6:581-588.

Klaenhammer, T. R., M. Kleerebezem, M. V. Kopp, and M. Rescigno. 2012. The impact of probiotics and prebiotics on the immune system. Nat. Rev. Immunol. 12:728-734.

Kuzmuk, K. N., K. S. Swanson, K. A. Tappenden, L. B. Schook, and G. C. Fahey. 2005. Diet and age affect intestinal morphology and large bowel fermentative end-product concentrations in senior and young adult dogs. J. Nutr. 135:1940-1945.

Laarman, A. H., A. Ruiz-Sanchez, T. Sugino, L. L. Guan, and M. Oba. 2012. Effects of feeding a calf starter on molecular adaptations in the ruminal epithelium and liver of Holstein dairy calves. J. Dairy Sci. 95:2585-2594.

Ley, R. E., M. Hamady, C. Lozupone, P. J. Turnbaugh, R. R. Ramey, J. S. Bircher, M. L. Schlegel, T. A. Tucker, M. D. Schrenzel, R. Knight, and J. I. Gordon. 2008. Evolution of mammals and their gut microbes. Science 320:1647-1651.

Li, M., G. B. Penner, E. Hernandez-Sanabria, M. Oba, and L. L. Guan. 2009. Effects of sampling location and time, and host animal on assessment of bacterial diversity and fermentation parameters in the bovine rumen. J. Appl. Microbiol. 107:1924-1934.

Luenser, K., and A. Ludwig. 2005. Variability and evolution of bovine beta-defensin genes. Genes Immun. 6:115-122.

Malmuthuge, N., Y. Chen, M. Li, P. Fries, P. J. Griebel, B. Baurhoo, X. Zhao, and L. L. Guan. 2012a. Distinct commensal bacteria associate with ingesta and mucosal epithelium throughout the gastrointestinal tract. FEMS Microbiol. Ecol. 79:337-347.

Malmuthuge, N., M. Li, P. Fries, P. J. Griebel, and L. L. Guan. 2012b. Regional and age dependent changes in gene expression of toll-like receptors and key antimicrobial defense molecules throughout the gastrointestinal tract of dairy calves. Vet. Immunol. Immunopathol. 146:18-26.

Maslowski, K. M., and C. R. Mackay. 2011. Diet, gut microbiota and immune responses. Nat. Immunol. 12:5-9.

Melmed, G., L. S. Thomas, N. Lee, S. Y. Tesfay, K. Lukasek, K. S. Michelsen, Y. Zhou, B. Hu, M. Arditi, and M. T. Abreu. 2003. Human intestinal epithelial cells are broadly unresponsive to tolllike receptor 2- dependent bacterial ligands: Implications for hostmicrobial interactions in the gut. J. Immunol. 170:1406-1415.

Miclard, J., M. Jaggi, E. Sutter, M. Wyder, B. Grabscheid, and H. Posthaus. 2009. Clostridium perfringens beta-toxin targets endothelial cells in necrotizing enteritis in piglets. Vet. Microbiol. 137:320-325.

Mucha, R., M. R. Bhide, E. B. Chakurkar, M. Novak, and I. Mikula Sr. 2009. Toll-like receptors TLR1, TLR2 and TLR4 gene mutations and natural resistance to Mycobacterium avium ssp. paratuberculosis infection in cattle. Vet. Immunol. Immunopathol. 128:381-388.

Noth, R., J. Lange-Grumfeld, E. Stuber, M. L. Kruse, M. Ellrichmann, R. Hasler, J. Hampe, B. Bewig, P. Rosenstiel, S. Schreiber, and A. Arlt. 2011. Increased intestinal permeability and tight junction disruption by altered expression and localization of occludin in a murine graft versus host disease model. BMC Gastroenterol. 11:109.

Osanai, A., H. Sashinami, K. Asano, S. Li, D. Hu, and A. Nakane. 2011. Mouse peptidoglycan recognition protein PGLYRP-1 plays a role in the host innate immune response against Listeria monocytogenes infection. Infect. Immun. 79:858-866.

Perdigón, G., E. Vintiñi, S. Alvarez, M. Medina, and M. Medici. 1999. Study of the possible mechanisms involved in the mucosal immune system activation by lactic acid bacteria. J. Dairy Sci. 82:11081114.

Pié, S., J. P. Lalles, F. Blazy, J. Laffitte, B. Seve, and I. P. Oswald. 2004. Weaning is associated with an upregulation of expression of inflammatory cytokines in the intestine of piglets. J. Nutr. 134:641-647.

Pinton, P., C. Braicu, J. P. Nougayrede, J. Laffitte, I. Taranu, and I. P. Oswald. 2010. Deoxynivalenol impairs porcine intestinal barrier function and decreases the protein expression of claudin- 4 through a mitogen-activated protein kinase-dependent mechanism. J. Nutr. 140:1956-1962.

Plain, K. M., A. C. Purdie, D. J. Begg, K. de Silva, and R. J. Whittington. 2010. Toll-like receptor (TLR) 6 and TLR1 differentiation in gene expression studies of Johne's disease. Vet. Immunol. Immunopathol. 137:142-148.

Rakoff-Nahoum, S., J. Paglino, F. Eslami-Varzaneh, S. Edberg, and R. Medzhitvo. 2004. Recognition of commensal microflora by toll-like receptors is required for intestinal homeostasis. Cell 118:229-241.

Renz, H., P. Brandtzaeg, and M. Hornef. 2011. The impact of perinatal immune development on mucosal homeostasis and chronic inflammation. Nat. Rev. Immunol. 12:9-23.

Sanders, M. E., and D. D. Levy. 2011. The science and regulations of probiotic food and supplement product labeling. Ann. N. Y. Acad. Sci. 1219(Suppl. 1):E1-E23

Sapone, A., K. M. Lammers, V. Casolaro, M. Cammarota, M. T. Giuliano, M. De Rosa, R. Stefanile, G. Mazzarella, C. Tolone, M. I. Russo, P. Esposito, F. Ferraraccio, M. Cartenì, G. Riegler, L. de Magistris, and A. Fasano. 2011. Divergence of gut permeability and mucosal immune gene expression in two gluten-associated conditions: Celiac disease and gluten sensitivity. BMC Med. 9:23.

Spreenwenberg, M. A. M. 2002. Diet composition and gut integrity in weaned piglets. PhD Thesis. Wageningen University, Wageningen, the Netherlands.

Stevenson, D. M., and P. J. Weimer. 2007. Dominance of Prevotella and low abundance of classical ruminal bacterial species in the bovine rumen revealed by relative quantification real-time PCR. Appl. Microbiol. Biotechnol. 75:165-174.

Ubeda, C., Y. Taur, R. R. Jenq, M. J. Equinda, T. Son, M. Samstein, A. Viale, N. D. Socci, M. R. M. van den Brink, M. Kamboj, and E. G. and Pamer. 2010. Vancomycin-resistant Enterococcus domination of intestinal microbiota is enabled by antibiotic treatment in mice and precedes bloodstream invasion in humans. J. Clin. Invest. 120:4332-4341.

Ulluwishewa, D., R. C. Anderson, W. C. McNabb, P. J. Moughan, J. M. Wells, and N. C. Roy. 2011. Regulation of tight junction permeability by intestinal bacteria and dietary components. J. Nutr. 141:769-776

Vandesompele, J., K. De Preter, F. Pattyn, B. Poppe, N. Van Roy, A. De Paepe, and F. Speleman. 2002. Accurate normalization of real-time quantitative RT-PCR data by geometric averaging of multiple internal control genes. Genome Biol. 3:research0034.

Walter, J., C. Hertel, G. W. Tannock, C. M. Lis, K. Munro, and W. P. Hammes. 2001. Detection of Lactobacillus, Pediococcus, Leuconostoc, and Weissella species in human feces by using group specific PCR primers and denaturing gardient gel electrophoresis. Appl. Environ. Microbiol. 67:2578-2585.

Walter, J., G. W. Tannock, A. Tilsala-Timisjarvi, S. Rodtong, D. M. Loach, K. Munro, and T. Alatossava. 2000. Detection and identification of gastrointestinal Lactobacillus species by using denaturing gradient gel electrophoresis and species-specific PCR primers. Appl. Environ. Microbiol. 66:297-303.

Wang, Y., S. Devkota, M. W. Musch, B. Jabri, C. Nagler, D. A. Antonopoulos, A. Chervonsky, and E. B. Chang. 2010. Regional mu- 
cosa-associated microbiota determine physiological expression of TLR2 and TLR4 in murine colon. PLoS ONE 5:e13607.

Wei, X., Z. Yang, F. E. Rey, V. K. Ridaura, N. O. Davidson, J. I. Gordon, and C. F. Semenkovich. 2012. Fatty acid synthase modulates intestinal barrier function through palmitoylation of mucin 2. Cell Host Microbe 11:140-152.

Weisburg, W. G., S. M. Barns, D. A. Pelletier, and D. J. Lane. 1991. $16 \mathrm{~S}$ ribosomal DNA amplification for phylogenetic study. J. Bacteriol. 173:697-703.
Xia, X. M., F. Wang, J. Zhou, K. Hu, S. Li, and B. Zou. 2011. CXCR4 antagonist AMD3100 modulates claudin expression and intestinal barrier function in experimental colitis. PLoS ONE 6:e27282.

Yang, D., O. Chertov, S. N. Bykovskaia, Q. Chen, M. J. Buffo, J. Shogan, M. Anderson, J. M. Schröder, J. M. Wang, O. M. Howard, and J. J. Oppenheim. 1999. Beta-defensins: Linking innate and adaptive immunity through dendritic and T cell CCR6. Science 286:525-528. 